\title{
Botryococcus braunii as a bioreactor for the production of nanoparticles with antimicrobial potentialities
}

This article was published in the following Dove Press journal: International Journal of Nanomedicine

\author{
Alejandra Arévalo-Gallegos' \\ J Saul Garcia-Perez' \\ Danay Carrillo-Nieves' \\ RA Ramirez-Mendoza' \\ Hafiz MN Iqbal' \\ Roberto Parra-Saldívar ${ }^{1-4}$ \\ 'Tecnologico de Monterrey, Escuela \\ de Ingenieria y Ciencias, Campus \\ Monterrey, Monterrey, Nuevo León, \\ Mexico; ${ }^{2}$ Microsystems Technologies \\ Laboratories, Massachusetts Institute \\ of Technology, Cambridge, MA, USA; \\ ${ }^{3}$ Department of Medicine, Brigham \\ and Women's Hospital, Harvard \\ Medical School, Cambridge, MA, \\ USA; ${ }^{4}$ Harvard-MIT Division of \\ Health Sciences and Technology, \\ Massachusetts Institute of Technology, \\ Cambridge, MA, USA
}

Background: Microalgae produce metabolites with notable potentialities to act as reducing and capping agents for the synthesis of silver nanoparticles (AgNPs) in a process widely recognized as an eco-friendly and cheaper alternative for the generation of nanoparticles (NPs).

Methods: In the present work, AgNPs were synthesized using live Botryococcus braunii cultures. Two biosynthesis routes were explored: (1) intracellular and (2) extracellular at pH levels of 6-9 using 1-5 mM silver nitrate concentrations.

Results: The generation of NPs was confirmed via ultraviolet-visible spectroscopy. The morphological characteristics were observed using scanning electron microscopy which revealed that the newly developed AgNPs were mostly spherical in sizes starting from $168 \mathrm{~nm}$. The characteristic peaks in a typical Fourier transform infrared spectroscopy suggested that the exopolysaccharides were the possible reducing and capping agents. The antimicrobial spectrum of the newly developed AgNPs was tested against bacterial strains, both Gram-negative, Gram-positive, and yeast, ie, Escherichia coli (American Type Culture Collection [ATCC] 25922), Pseudomonas aeruginosa (ATCC 27853), Staphylococcus aureus (ATCC 25923), and the yeast Candida albicans (ATCC 10231), respectively. The antimicrobial activity tests showed a stronger inhibition against Gram-negative bacteria. Statistically, the NPs biosynthesized at $\mathrm{pH}$ values of 6 and 8 displayed a higher antimicrobial activity.

Conclusion: Our findings showed that B. braunii is capable of generating AgNPs with antimicrobial potential.

Keywords: biosynthesis, microalgae, silver nanoparticles, antimicrobial activity

\section{Introduction}

Metallic nanoparticles (NPs) are among the most widely commercialized nanomaterials today, with applications in industries as varied as cosmetics, food packaging, textiles, and so on. ${ }^{1-3}$ Based on the number of applications, there are four main types of metallic NPs: iron oxide $\left(\mathrm{Fe}_{2} \mathrm{O}_{3}\right)$, gold NPs (AuNPs), silver NPs (AgNPs), and selenium NPs (SeNPs). Each of them exhibit unique physicochemical, magnetic, optical, and biological properties that differ from those of the bulk material, such as quantum effects and a higher surface area, granting them increased antimicrobial and catalytic activity in certain cases, such as AgNPs and SeNPs. ${ }^{4,5}$

AgNPs are generally known for their antimicrobial, potential, optical properties and biocompatibility and have been successfully integrated to several technologies such as medical devices, electrodomestic devices, and paint additives. ${ }^{6-8} \mathrm{Ag}$ is known to inhibit bacterial cell division and lead to cell death due to the generation of reactive oxygen species, inducing high intracellular calcium levels, loss of membrane potential, the activation of caspase-like proteins, and DNA fragmentation. ${ }^{9}$ Products \footnotetext{
Hafiz MN lqbal

Tecnologico de Monterrey, School of Engineering and Sciences, Campus Monterrey, Avenue Eugenio Garza Sada 250I, Monterrey, Nuevo León; CP 64849, Mexico

Tel +52 8I8 3582000 ext 5534 Fax +528183582000 ext 5560 Email r.parra@itesm.mx; hafiz.iqbal@itesm.mx
}

Correspondence: Roberto Parra-Saldívar; 
with antimicrobial capacity have many advantages, including a longer shelf life, protection against colonization of bacteria, and bacterial degradation. ${ }^{10}$ Nowadays, AgNPs are the only metallic NPs currently commercialized as gels and dressings for the treatment of burns and wounds due to their biocompatibility, inexpensiveness, and antibacterial activity. ${ }^{11}$ As more pathogenic strains continue to develop antibiotic resistance, the search for novel antimicrobial agents is increasing. AgNPs are considered among the most promising antimicrobial agents. ${ }^{12}$

The current synthesis methods for generating metallic NPs can be divided into two categories: 1) physical and 2) chemical. Physical methods, such as evaporation-condensation and laser ablation, consume large amounts of energy and take a long time for completion. Chemical methods, achieved by the reduction of metallic salts, require the use of chemicals such as sodium citrate and sodium borohydride, as well as the addition of stabilizers and capping agents; the waste generated by chemical reduction is also dangerous for the environment. ${ }^{13}$ The resulting NPs may also present chemical residues on the surface, disabling their clinical use. ${ }^{14}$ On the pursuit of more sustainable and eco-friendly chemical processes, research has focused on developing a cheaper and nontoxic method for developing NPs. Biological synthesis is an environmentally safe process with lower costs and lower toxicity.

The reports indicate that biosynthesized NPs are more biocompatible and therefore more suitable for drug delivery, bio-imaging, and cancer treatment applications. ${ }^{15}$ Furthermore, biosynthesized NPs can be of varied morphologies and sizes and possess higher catalytic activity. There are many reports on the biosynthesis of NPs with organic extracts or microorganisms, including plants, fungi, yeast, virus, and bacteria. ${ }^{14}$ There are two methods for the biosynthesis of metallic NPs with a living organism: 1) the intracellular mode which consists of adding metallic salts to the culture medium for the microorganism to absorb it and reduce it; and 2) the extracellular mode in which the reduction is carried out with metabolites secreted by the microorganism, or with derived components. ${ }^{16}$

Microalgae are photosynthetic organisms naturally capable of reducing metals due to the constant exposure to them in their natural environment; ${ }^{17}$ due to this characteristic, algae are often used for water bioremediation and sorption of toxic and radioactive metal ions. ${ }^{18}$ Botryococcus braunii is a green microalgae known for its ability to produce high amounts of hydrocarbons, which are similar to fossil oil; ${ }^{19}$ it forms colonies of individual cells joined together by an extracellular matrix (ECM) composed of polysaccharides, polyaldehydes, and liquid hydrocarbons. ${ }^{20}$ The unique composition of the ECM and the microalgae's ability to accumulate metabolites with functional groups that are known to be able to reduce metallic salts indicate that this organism could prove to be a functional way of obtaining NPs.

Herein, an effort has been made to explore the potential of environmentally friendly biosynthesized AgNPs under different silver nitrate concentrations and $\mathrm{pH}$ conditions to control the shape and other properties of the resulting AgNPs under both the intracellular and the extracellular methods with $B$. braunii. The resulting NPs were fully characterized using imaging and instrumental techniques. Moreover, aiming to present the applied perspectives, the antimicrobial spectrum of the newly developed AgNPs was tested against bacterial strains, both Gram-negative and Gram-positive, ie, Escherichia coli (American Type Culture Collection [ATCC] 25922), Pseudomonas aeruginosa (ATCC 27853), and Staphylococcus aureus (ATCC 25923), and the yeast Candida albicans (ATCC 10231), respectively.

\section{Materials and methods Chemical reagents}

Silver nitrate, ampicillin, Luria-Bertani (LB) broth, yeast extract-peptone-dextrose (YPD), LB broth agar, sodium nitrate, calcium nitrate, magnesium sulfate heptahydrate, potassium sulfate, and a $20 \mathrm{~nm}$ AgNP solution were all purchased from Sigma-Aldrich (Toluca, Mexico). The pathogenic strains of E. coli (ATCC 25922), P. aeruginosa (ATCC 27853), S. aureus (ATCC 25923), and the yeast C. albicans (ATCC 10231) were all purchased from ATCC (Manassas, VA, USA). B. braunii (the University of Texas [UTEX] 572) was obtained from the culture collection at the UTEX at Austin, TX, USA. Sulfuric acid, barium chloride, and sodium chloride were purchased from CTR (Monterrey, Mexico).

\section{Algal culture and growth conditions}

$B$. braunii was maintained under the following culture conditions: $25^{\circ} \mathrm{C}$, a light intensity of $150 \mu \mathrm{mol} / \mathrm{m}^{2} \mathrm{~s}$ with a 12:12-hour light/dark cycle under cool fluorescent light, and a constant aeration with a pump in a Bold $3 \mathrm{~N}$ Medium: $\mathrm{NaNO}_{3}(8.82 \mathrm{mM}), \mathrm{CaCl}_{2} \cdot 2 \mathrm{H}_{2} \mathrm{O}(0.17 \mathrm{mM}), \mathrm{MgSO}_{4} \cdot 7 \mathrm{H}_{2} \mathrm{O}$ (0.3 mM), $\mathrm{K}_{2} \mathrm{HPO}_{4}(0.43 \mathrm{mM}), \mathrm{KH}_{2} \mathrm{PO}_{4}(1.29 \mathrm{mM})$, and $\mathrm{NaCl}$ $(0.43 \mathrm{mM}) .{ }^{21}$ Regular subculturing techniques were applied in order to maintain the culture in a growth phase. A separate $B$. braunii culture was established with a modified version 
of the Bold $3 \mathrm{~N}$ Medium lacking in $\mathrm{NaCl}$ and $\mathrm{CaCl}_{2} \cdot 2 \mathrm{H}_{2} \mathrm{O}$ for the extracellular synthesis of AgNPs.

\section{Biomass analysis}

After 23 days of cultivation, the biomass was harvested for sugars and proteins, and Fourier transform infrared (FTIR) spectroscopy was used for analysis. The total carbohydrate content was quantified with the phenol-sulfuric method and the total protein content by the Lowry method. ${ }^{22,23}$ The FTIR spectra were obtained using a PerkinElmer Spectrum 400 FTIR - Attenuated Total Reflectance (ATR)/near infrared (NIR) instrument (Shelton, CT, USA).

\section{Biosynthesis of AgNPs}

The biosynthesis protocol was based on the methods previously described. ${ }^{24}$ The $B$. braunii culture in log phase was centrifuged at $846 \times g$ for 5 minutes and washed twice with Milli-Q water to remove the culture medium. Afterward, $\sim 5 \mathrm{~g}$ of wet biomass was resuspended in $100 \mathrm{~mL}$ of sterile water. Then, a sterile $\mathrm{AgNO}_{3}$ solution was added to reach the desired concentration. The reaction mixture was incubated for 48 hours at $20^{\circ} \mathrm{C}$ under constant stirring at $180 \mathrm{rpm}$ and at a light intensity of $300 \mu \mathrm{mol} / \mathrm{m}^{2} \mathrm{~s}$. Then, a $1 \mathrm{~mL}$ reaction solution was harvested, centrifuged at $9,402 \times g$ for 20 minutes (Prism C2500-R; Labnet, Edison, NJ, USA), resuspended in Milli-Q water $\left(18.2 \mathrm{M} \Omega \mathrm{cm}^{-1}\right)$, sonicated to break the cells, and filtered with 0.45 and $0.22 \mu \mathrm{m}$ pore sizes. An absorbance scan was taken between 200 and $800 \mathrm{~nm}$ using a spectrophotometer (Varioskan Flash; Thermo Fisher Scientific, Waltham, MA, USA). The rest of the solution was centrifuged to recover the AgNPs, freeze-dried (FreeZone Triad Cascade Benchtop Freeze Dryer; Labconco, Kansas City, MO, USA), and stored for future analysis. For the extracellular synthesis, $100 \mathrm{~mL}$ of $\mathrm{NaCl}-/ \mathrm{CaCl}_{2}$-free culture was taken, centrifuged ( $846 \times g, 5$ minutes), and filtered (pore size $=0.22 \mu \mathrm{m}$ ) to eliminate algal cells. Then, the same procedure was followed. The following controls were established: biomass with sterile water, a cell-free extract with sterile water, and a sterile $\mathrm{AgNO}_{3}$ solution with water.

\section{Characterization of AgNPs}

\section{Scanning electron microscopy (SEM) analysis}

SEM analysis was carried out with a ZEISS EVO ${ }^{\circledR}$ MA 25 (Ostalbkreis, Baden-Württemberg, Germany) using an acceleration voltage of $20 \mathrm{kV}$ and an electron backscatter diffraction detector. A drop of the final AgNPs solution was added to carbon tape and left to dry. No coating with gold was necessary.

\section{FTIR spectroscopy}

The analysis by FTIR was performed using a PerkinElmer Spectrum 400 FTIR - ATR/NIR instrument. All spectra were obtained through a four-scan measurement from 380 to $4,000 \mathrm{~cm}^{-1}$ with a resolution of $4 \mathrm{~cm}^{-1}$. The analysis was performed with the PerkinElmer spectrum software.

\section{Antimicrobial activity}

The biosynthesized AgNPs were tested with three bacterial strains: E. coli (ATCC 25922), P. aeruginosa (ATCC 27853), and $S$. aureus (ATCC 25923), and the yeast C. albicans (ATCC 10231) using the agar well diffusion method. ${ }^{25}$ Briefly, an initial culture was established in liquid LB medium for the bacteria and in YPD medium for the yeast in order to reactivate the strain. After 24 hours, the culture was compared with the McFarland standard, and if necessary, sterile water was added to dilute the culture. Then, sterile Petri dishes with LB agar (YPD for the yeast) were inoculated with the microorganisms. After 15 minutes, 6-mm-diameter wells were perforated in the agar, and $100 \mu \mathrm{L}$ of each solution was added (samples and controls). The concentration of all biosynthesized AgNPs was $1 \mu \mathrm{g} / \mathrm{mL}$. Three controls were used in this assay: a negative control (water) and two positive controls $(2 \mu \mathrm{g} / \mathrm{mL}$ ampicillin and a commercial AgNP solution [20 nm particle size, $0.02 \mathrm{mg} / \mathrm{mL}$, purchased from Sigma-Aldrich]). Plates were incubated for 24 hours at $37^{\circ} \mathrm{C}$. Afterward, the inhibition halo was measured. An inhibition halo of $<6 \mathrm{~mm}$ was considered as not active against each test strain.

\section{Statistical analysis}

All experiments were performed in triplicate. Data were summarized as the mean $\pm \mathrm{SD}$. Statistical analysis was performed using an analysis of variance with Bonferroni post hoc tests with an $\alpha=0.05$ using IBM SPSS Statistics software for Macintosh, Version 22.0 (IBM Corp, Armonk, NY, USA).

\section{Results and discussion Algal culture}

Figure 1 shows the growth curve of $B$. braunii. Several studies have shown that the exponential phase of $B$. braunii cultures starts around day 3 and continues until day 22. Then, cell growth decreases and can remain stationary or erratic for the next days. ${ }^{26}$ This tendency appeared in our cultures as well; therefore, the biomass was harvested between days 20 and 24 in order to use cells in an exponential phase and 


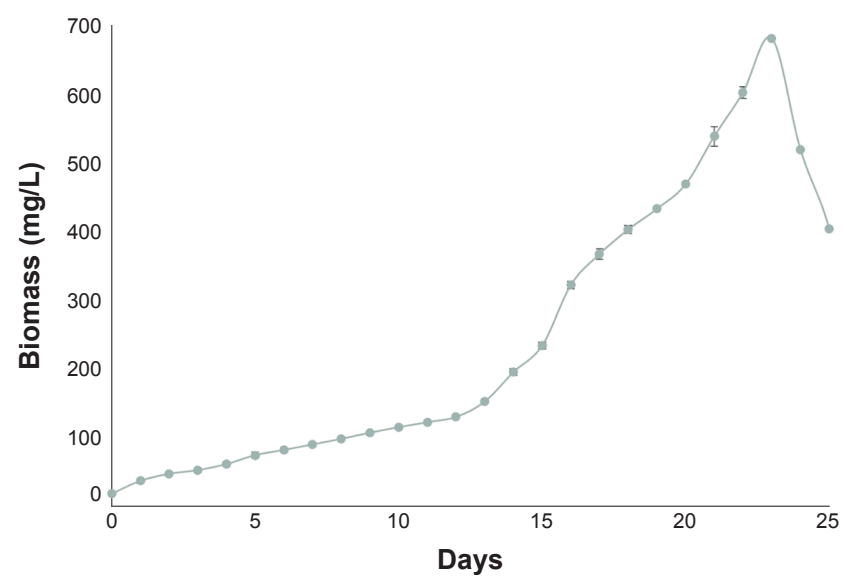

Figure I Growth curve for Botryococcus braunii grown in the Modified Bold 3N Medium.

to remain consistent with other biosynthesis experiments reported. ${ }^{4}$ An alternate culture was established with a modified version of the Bold $3 \mathrm{~N}$ Medium for the extracellular biosynthesis experiments.

This was done in order to avoid the reaction between the chloride ions and the silver nitrate. This reaction could be interpreted as false-positive given the fact that it forms precipitates in the solution. The $B$. braunii culture grown in this modified Bold 3N Medium showed a slower growth rate, as has been previously reported; ${ }^{27}$ however, the culture medium was harvested when the culture was at the exponential phase to maintain consistency among the experiments.

\section{Biomass analysis}

$B$. braunii synthesizes a fibrillary layer made of polysaccharides in the cell wall, which slowly dissolves into the culture medium, causing an increase in viscosity and forming the ECM. When nitrate is used as a nitrogen source, both cell growth and exopolysaccharide (EPS) production occur; a higher production of EPS can be observed as the growth rate declines, consistent with the occurrence of nitrogen limitation due to cell growth in the medium. ${ }^{28}$ During nitrogen starvation, the photosynthetic compounds in the cell decrease, causing a reduction in the rate of photosynthesis. The cell responds by accumulating carbon-containing compounds as a reserve, such as polysaccharides. In the present study, the total amount of sugars was estimated at $310.8 \pm 10.4 \mathrm{mg} / \mathrm{L}$, calculated at the end of the exponential phase. This amount is similar to what another study reported: After 18 days of cultivation under similar conditions, an amount of $282 \mathrm{mg} / \mathrm{L}$ of sugars was reported for the same strain of B. braunii. ${ }^{20}$ The total amount of protein was estimated at $347.40 \pm 0.14 \mathrm{mg} / \mathrm{L}$. This is a higher amount compared with other studies in which the microalgae was cultivated under similar conditions: $60 \mathrm{mg} / \mathrm{L}$ of protein in the cell-free medium, determined by the Bradford assay, was reported by Dayananda et al. ${ }^{21}$ However, higher amounts of protein for this strain of B. braunii can also be found in the literature: A study by Allard and Casadevall ${ }^{29}$ determined $86 \%$ of the weight of an extracellular B. braunii extract with the Lowry assay.

\section{Biosynthesis of AgNPs}

To the best of our knowledge, there is only one report regarding the biosynthesis of AgNPs with B. braunii. In that study, the microalgae's capacity for biosynthesis was evaluated in the presence and absence of light. ${ }^{17}$ Results indicated that $B$. braunii was capable of generating NPs only in the presence of light; therefore, all the experiments performed in this study were done in illuminated conditions; however, the effect of $\mathrm{pH}$ and silver nitrate was not explored further, as they carried out their experiments at a $\mathrm{pH}$ of 7 and with $1 \mathrm{mM}$ of silver nitrate. In the present study, the effects of several concentrations of silver nitrate and levels of $\mathrm{pH}$ on the shape and size of AgNPs were investigated.

\section{Intracellular biosynthesis}

The biosynthesis reaction was carried out with several concentrations of silver nitrate and several $\mathrm{pH}$ levels. Table 1 presents the order of the experiments. After an 8-hour incubation, NP formation was confirmed via ultraviolet-visible (UV-Vis) spectroscopy, with the characteristic peak indicating the surface plasmon resonance at $400 \mathrm{~nm}$ (Figure 2). ${ }^{31}$ The solution's color changed from green to dark brown, indicating the reduction of the silver nitrate. The total incubation time for all the experiments was set at 48 hours.

In accordance with the literature, optical microscopy images indicated that the intracellular synthesis of AgNPs occurred in the chloroplast and in the cell wall. This can be explained taking into account the fact that enzymes with

Table I Experimental parameters utilized for the intracellular biosynthesis of AgNPs

\begin{tabular}{lll}
\hline Run & Parameters & \\
\cline { 2 - 3 } & pH & AgNO $_{3}$ (mM) \\
\hline 1 & 9 & 1 \\
2 & 9 & 5 \\
3 & 9 & 3 \\
4 & 8 & 3 \\
5 & 7 & 5 \\
6 & 7 & 1 \\
7 & 6 & 3 \\
\hline
\end{tabular}

Abbreviation: AgNPs, silver nanoparticles. 

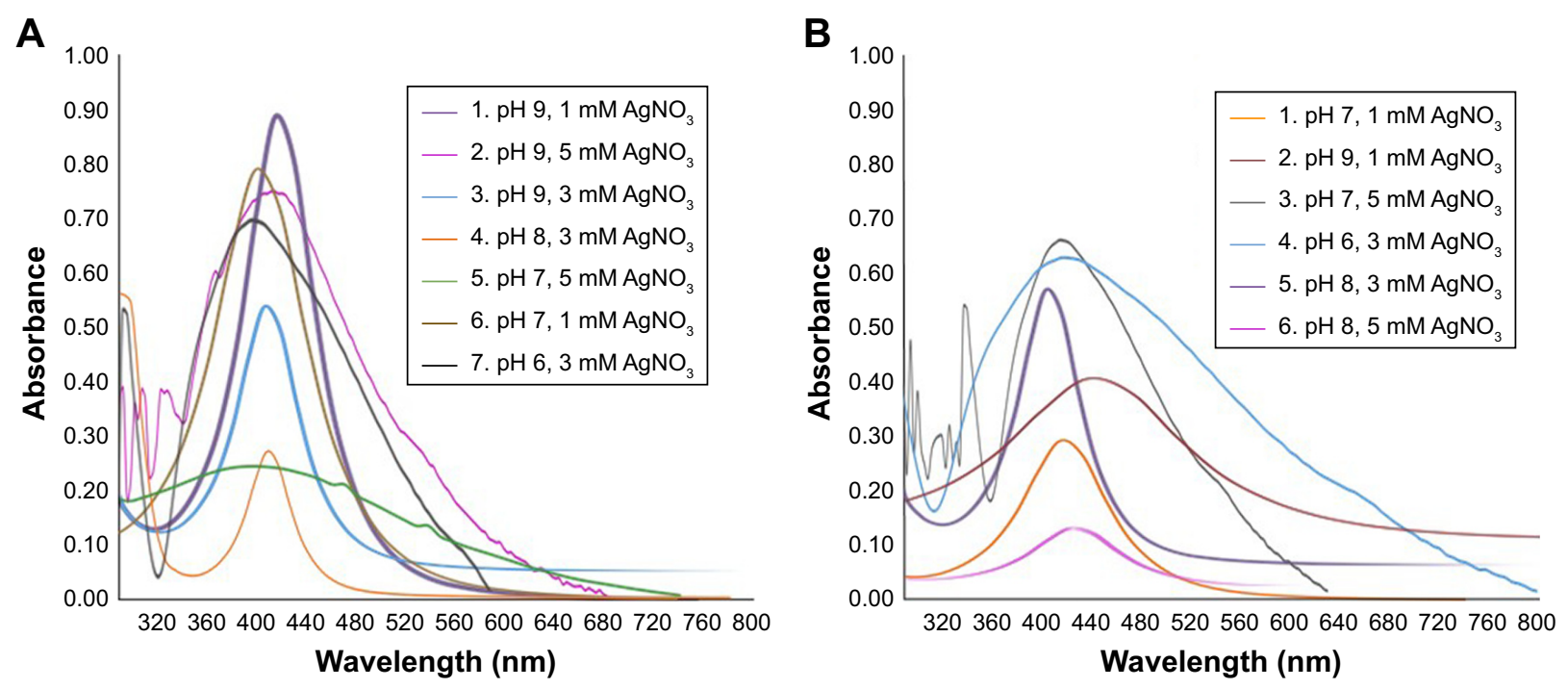

Figure 2 UV-Vis spectra recorded after an 8-hour incubation for (A) intracellular biosynthesis and a 4-hour incubation for (B) extracellular biosynthesis. Abbreviation: UV-Vis, ultraviolet-visible.

redox activity are responsible for the reduction of silver nitrate and the consequent formation of NPs. ${ }^{24}$ The chloroplast contains the cellular machinery responsible for photosynthetic activity and therefore contains a high number of biomolecules with a redox activity. It has been reported that when subjected to stress due to the presence of heavy metals, the photosynthetic machinery inside the chloroplast is the first to respond, overexpressing proteins such as adenosine triphosphate synthase, RUBP carboxylase, and an oxygenevolving enhancer protein, leading to the synthesis of NPs. ${ }^{35}$ It is also known that microalgae accumulate heavy metals in internal granules as a defense mechanism; ${ }^{36}$ however, we did not observe such a phenomenon in this study, probably because the culture was not incubated with silver nitrate for an extended period of time. Other studies indicate that longer contact times with heavy metals cause a higher biosorption capacity. ${ }^{18}$

We also observed that the Ag was accumulated in the extracellular environment around the cell colonies, meaning that there was an interaction between the Ag ions and the molecules forming the ECM. Most of the cells remained intact and preserved their green color after exposure to $\mathrm{Ag}$; nonetheless, in those experiments with the highest concentrations of silver nitrate, some of the cells burst. The reason for the accumulation of nanosilver in the cell wall is the fact that this organelle contains biomolecules with redox capacity which means the cell wall is able to play a role in the biosynthesis of NPs. The composition of the ECM varies depending on the strain of $B$. braunii: for the specific case of B. braunii UTEX 572 (Race A), a carbohydrate profile of fucose (4 mg/L), rhamnose (3 mg/L), arabinose (10 mg/L), galactose $(107 \mathrm{mg} / \mathrm{L})$, and glucose $(158 \mathrm{mg} / \mathrm{L})$ has been reported. ${ }^{20}$ Such molecules present functional groups that grant a negative charge to the cell surface, such as carboxyl, hydroxyl, amino, and phosphate. This negative charge allows for a great binding ability for metal cations. ${ }^{37}$

The incubation time for all experiments was set at 48 hours. We observed that at the lower concentrations of silver nitrate, the cells managed to retain their structure; however, the culture lost its characteristic green color, perhaps a sign of the loss of function of the photosynthetic machinery due to the interaction with the Ag. In the cultures subjected to a higher concentration of silver nitrate, the cells were not able to maintain their integrity and burst, releasing the cellular content into the culture medium.

NPs created under basic $\mathrm{pH}$ levels presented a more uniform shape and size compared with those synthesized under acidic conditions. This is consistent with another report of biogenic synthesis, which suggested, that at a basic $\mathrm{pH}$ level, the reduction of silver nitrate is more stable. ${ }^{30}$ Likewise, basic $\mathrm{pH}$ conditions also seemed to yield a higher number of NPs as well as a faster reduction of the Ag. ${ }^{38}$ Regarding the concentration of silver nitrate, we observed that at a higher concentration the absorption peak measured with UV-Vis spectroscopy increased. This phenomenon has been previously reported. ${ }^{34}$

When the concentration of silver nitrate was increased from 1 to $5 \mathrm{mM}$, at a fixed $\mathrm{pH}$ level of 7 , the shape obtained resembled more a cube and seemed to have a more crystalline structure. In comparison with the AgNPs intracellularly 
synthesized, the extracellularly biosynthesized NPs were overall less stable, presenting agglomeration in a shorter period of time as well as presenting a higher size. This is consistent with studies carried out in the microalgae Scenedesmus sp..$^{35}$

The generation of AgNPs was not achieved with all the experiments. As can be seen in Figure 3, needlelike structures were obtained at a neutral $\mathrm{pH}$ and with $5 \mathrm{mM}$ of silver nitrate. While these structures cannot be considered NPs due to their size, they do resemble nanorods. Previously, silver vanadium oxide nanorods have been synthesized with a sonochemical method. ${ }^{39}$ Despite this result, overall, the intracellular synthesis yielded smaller NPs, with a predominantly spherical shape.
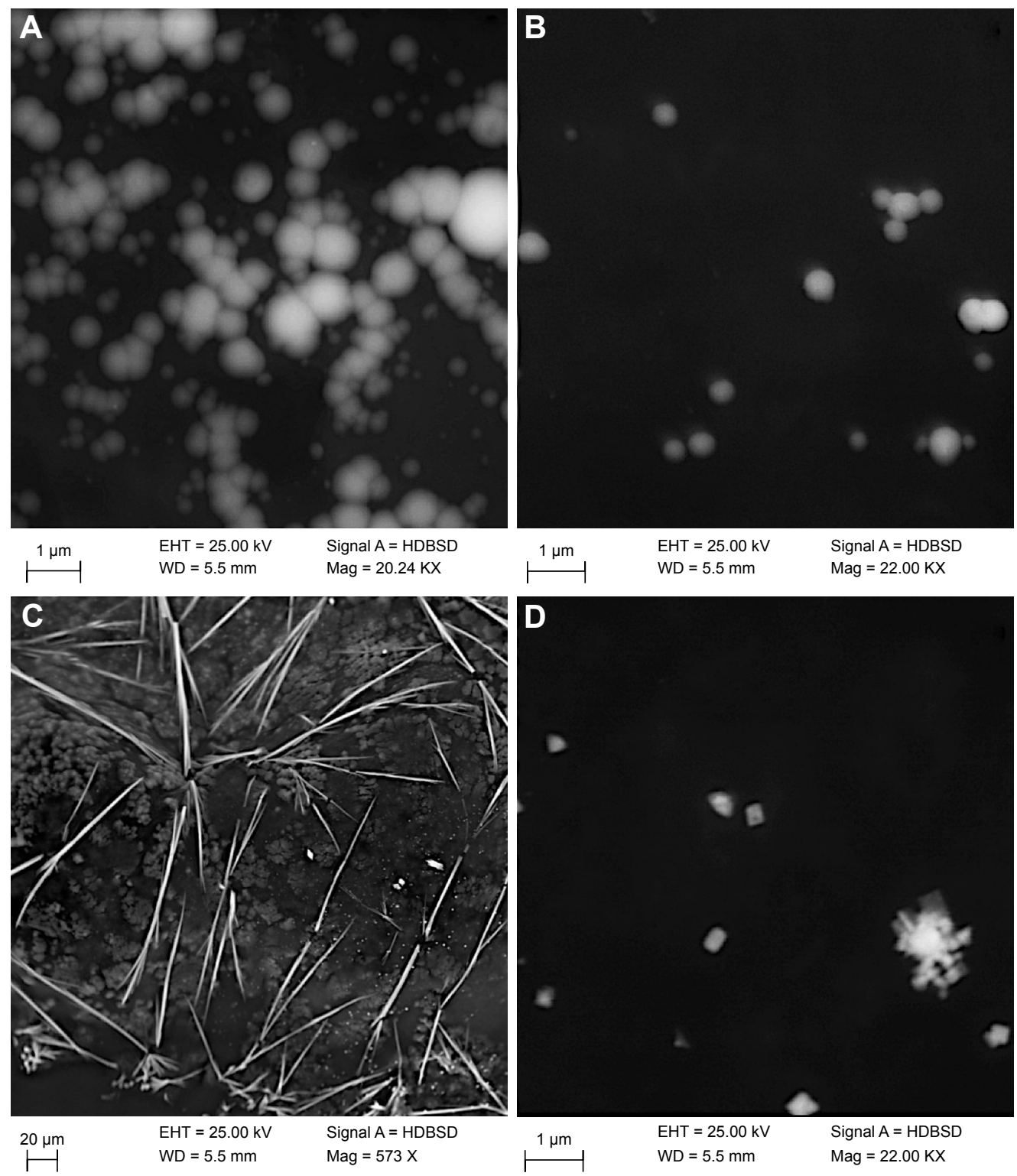

Figure 3 Scanning electron microscopy images of intracellularly biosynthesized silver nanoparticles: (A) run I ( $\mathrm{pH}^{9}, \mathrm{I} \mathrm{mM} \mathrm{AgNO}$ ), (B) run 3 ( $\mathrm{pH} 9,3 \mathrm{mM} \mathrm{AgNO}$ ), (C) run $5\left(\mathrm{pH} \mathrm{7,5} \mathrm{mM} \mathrm{AgNO}_{3}\right)$, and (D) run $6\left(\mathrm{pH} \mathrm{7,} \mathrm{I} \mathrm{mM} \mathrm{AgNO}_{3}\right)$.

\section{Extracellular biosynthesis}

For the extracellular synthesis of AgNPs, several combinations of silver nitrate and $\mathrm{pH}$ were analyzed (Table 2 ). Reactions were incubated for 48 hours at a constant temperature $\left(21^{\circ} \mathrm{C}\right)$ and light. Extracellular biosynthesis of AgNPs was a faster process compared with the intracellular pathway. After 4 hours, the characteristic peak at 300-400 nm appeared (Figure 2B) and became more pronounced as time progressed, indicating a growing number of NPs suspended in the solution. At a $\mathrm{pH}$ level of 7, when the silver nitrate was at the lowest concentration, a hexagonal or flake-like shape was obtained, very similar to nanosilver flakes commonly used in the optics industry because of their electrical conductivity (Figure 3A). Nanosilver flakes are prepared by the wet chemical method, light/heat

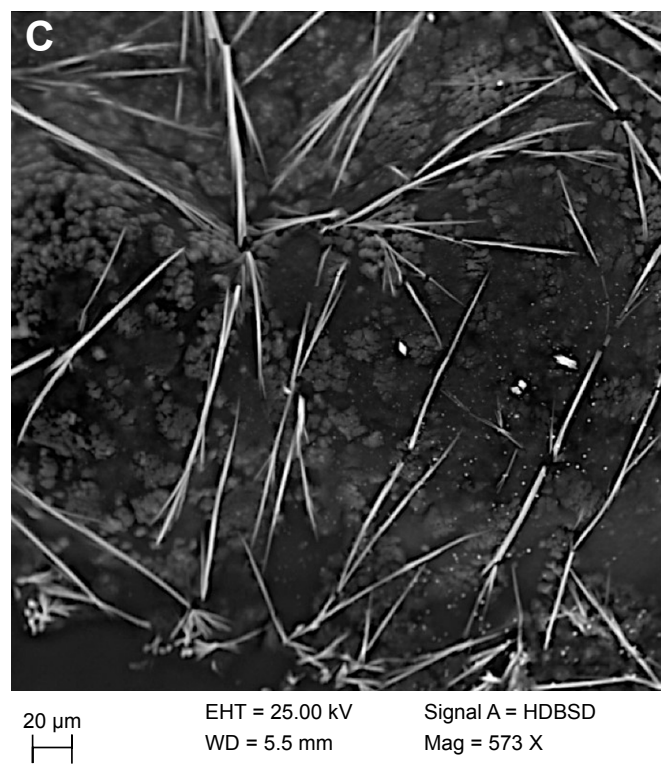


Table 2 Experimental parameters set for the extracellular biosynthesis of AgNPs

\begin{tabular}{lll}
\hline Run & Parameters & \\
\cline { 2 - 3 } & $\mathbf{p H}$ & $\mathbf{A g N O}_{3}(\mathbf{m M})$ \\
\hline 1 & 7 & 1 \\
2 & 9 & 1 \\
3 & 7 & 5 \\
4 & 6 & 3 \\
5 & 8 & 3 \\
6 & 8 & 5 \\
\hline
\end{tabular}

Abbreviation: AgNPs, silver nanoparticles.

induction, and heterogeneous nucleation, all chemical reduction methods. ${ }^{40}$ As a follow-up to this investigation, it would be convenient to test the conductivity of the biosynthesized NPs in order to evaluate potential applications, both in optics and in tissue engineering. ${ }^{41}$ While the particles obtained in this study do resemble nanosilver flakes, it is necessary to carry out more experiments in order to determine the conditions in which a more uniform size and shape can be obtained.

We theorized that the molecules responsible for the extracellular synthesis were the EPS produced by B. braunii as part of its complex ECM. There are several reports of the synthesis of AgNPs with EPS, most of them involving bacteria-derived EPS, such as Pseudomonas fluorescens, Lactobacillus rhamnosus, and Bacillus subtilis. ${ }^{42-44}$ There are fewer reports with microalgae-derived EPS; however, a study by Brayner et al reported the biogenic synthesis of AuNPs, AgNPs, palladium NPs, and platinum NPs with Anabaena, Calothrix, and Leptolyngbya cultures and confirmed that the particles were stabilized by the algal polysaccharides. ${ }^{45}$ In addition, it has been suggested that reducing sugars can function as electron donors in the reduction of $\mathrm{Ag}$ to its metallic form $\left(\mathrm{Ag}^{0}\right)$; at higher $\mathrm{pH}$ levels, the monosaccharide ring (such as glucose) opens, leaving a chain of aldehydes. In the presence of metal ions, these aldehydes form carboxylic acids, causing the reduction of Ag. ${ }^{38}$

Overall, more positive results in terms of uniform size and shape were obtained with the intracellular synthesis route, possibly due to the presence of active biomolecules such as redox enzymes. However, carrying out extracellular synthesis remains a potentially beneficial alternative due to the fact that it allows for higher concentrations of $\mathrm{Ag}$ to be used, as well as more extreme conditions such as a higher or lower $\mathrm{pH}$ and temperature, which could accelerate the reaction, ${ }^{38}$ therefore, more experiments are needed in order to optimize this process.

\section{Characterization of AgNPs SEM}

According to the combination of $\mathrm{pH}$ levels and concentration of silver nitrate, we obtained several types of AgNPs, in terms of shape and size. A uniform size distribution was not obtained in all the experiments. For the intracellularly synthesized AgNPs, the more predominant shape obtained was spheres, as seen in run 1 (Figure 3A) and run 3 (Figure 3B), this last one presenting a more uniform size distribution compared with the other samples. Run 5 also yielded a type of nanostructure very uniform in size and shape, but too big to be considered an NP (Figure 3C). Run 6 (Figure 3D) produced a set of nanostructures with various shapes, leaning toward a square or perhaps a cubic appearance. Table 3 presents the results in terms of AgNPs' shape for both types of biosynthesis.

Regarding the extracellularly synthesized AgNPs, while a uniform size distribution was not obtained, more interesting shapes were discovered. Run 1 (pH 7, 1 mM AgNO ; Figure 4A) yielded structures similar to nanosilver flakes synthesized by the chemical reduction method..$^{40}$ Runs 3 $\left(\mathrm{pH} 7,5 \mathrm{mM} \mathrm{AgNO}_{3}\right)$ and $2(\mathrm{pH} 9,1 \mathrm{mM} \mathrm{AgNO}$; Figure 4B and $\mathrm{C}$, respectively) yielded cubic structures, albeit of very different sizes: run 2 produced large, porous cubic-like nanostructures, while run 3 produced small, solid, seemingly cubic structures. The difference in intensity between the samples of these two runs indicates that those NPs obtained from run 3 contained more $\mathrm{Ag}$ compared with those from run 2 despite following the usual purification method. ${ }^{24,46}$ Run 5 produced NPs with less defined shapes, but a higher concentration of Ag according to the intensity shown in the images (Figure 4D). The gray areas around the NPs indicate a further need for purification, although they do seem to contain trace amounts of Ag.

Comparing with the previously mentioned article which used $B$. braunii biomass as a substrate for the generation of AgNPs, the NPs obtained in the present study were notoriously bigger. This difference can be perhaps attributed to the amount of biomass used in both studies: The amount of $\mathrm{Ag} /$ biomass ratio can also influence the final shape of the NPs; for example, in some cases, Ag may become the limiting reagent. Patel et a ${ }^{17}$ did not report the amount of biomass used for the experiments.

\section{FTIR spectroscopy}

In order to determine which molecules were responsible for capping and/or stabilizing the biosynthesized AgNPs, FTIR spectroscopy was carried out for the following selected samples: intracellular run $5(\mathrm{pH} 7,5 \mathrm{mM})$ and extracellular run 1 (pH 7, $1 \mathrm{mM}$ ), and the samples were then compared with the dry biomass from B. braunii. The AgNPs and the biomass FTIR spectra is shown in Figure 5. In the biomass spectra, the broad peak at $3223 \mathrm{~cm}^{-1}$ indicated the stretch of an $\mathrm{OH}$ group, perhaps belonging to polyphenols or polysaccharides. . $^{30,34} \mathrm{At}$ 
Table 3 Characterization of biosynthesized AgNPs in terms of appearance and approximate size

\begin{tabular}{|c|c|c|c|c|c|c|c|}
\hline \multirow[t]{2}{*}{ Run } & \multicolumn{2}{|l|}{ Intracellular } & \multirow[t]{2}{*}{ Size $(\mathrm{nm})$} & \multirow[t]{2}{*}{ Run } & \multicolumn{2}{|l|}{ Extracellular } & \multirow[t]{2}{*}{ Size $(\mathrm{nm})$} \\
\hline & Parameters & Appearance & & & Parameters & Appearance & \\
\hline $\mathrm{I}$ & $\mathrm{pH} 9, \mathrm{I} \mathrm{mM}$ & Spherical & $433-645$ & I & $\mathrm{pH} 7, \mathrm{I}$ mM & Hexagonal disks & 347 \\
\hline 2 & $\mathrm{pH} 9,5 \mathrm{mM}$ & Amorphous & NA & 2 & $\mathrm{pH} 9, \mathrm{I} \mathrm{mM}$ & Cubes & $800-1,500$ \\
\hline 3 & $\mathrm{pH} 9,3 \mathrm{mM}$ & Spherical & $644-915$ & 3 & $\mathrm{pH} 7,5 \mathrm{mM}$ & Cubes & $300-486$ \\
\hline 4 & $\mathrm{pH} 8,3 \mathrm{mM}$ & Spherical & NA & 4 & $\mathrm{pH} \mathrm{6,} 3 \mathrm{mM}$ & Amorphous & 734 \\
\hline 5 & $\mathrm{pH} 7,5 \mathrm{mM}$ & Large needles & NA & 5 & $\mathrm{pH} 8,3 \mathrm{mM}$ & Square & $243-542$ \\
\hline 6 & $\mathrm{pH} 7, \mathrm{I} \mathrm{mM}$ & Spherical & 168 & 6 & $\mathrm{pH} 8,5 \mathrm{mM}$ & Amorphous & NA \\
\hline 7 & $\mathrm{pH} 6,3 \mathrm{mM}$ & Spherical & NA & & & & \\
\hline
\end{tabular}

Notes: The appearance of the AgNPs was described as seen during the analysis with SEM. A drop of the final AgNP solution in Milli-Q water was dropped to the pin and was then analyzed with SEM.

Abbreviations: AgNPs, silver nanoparticles; NA, not applicable; SEM, scanning electron microscopy.
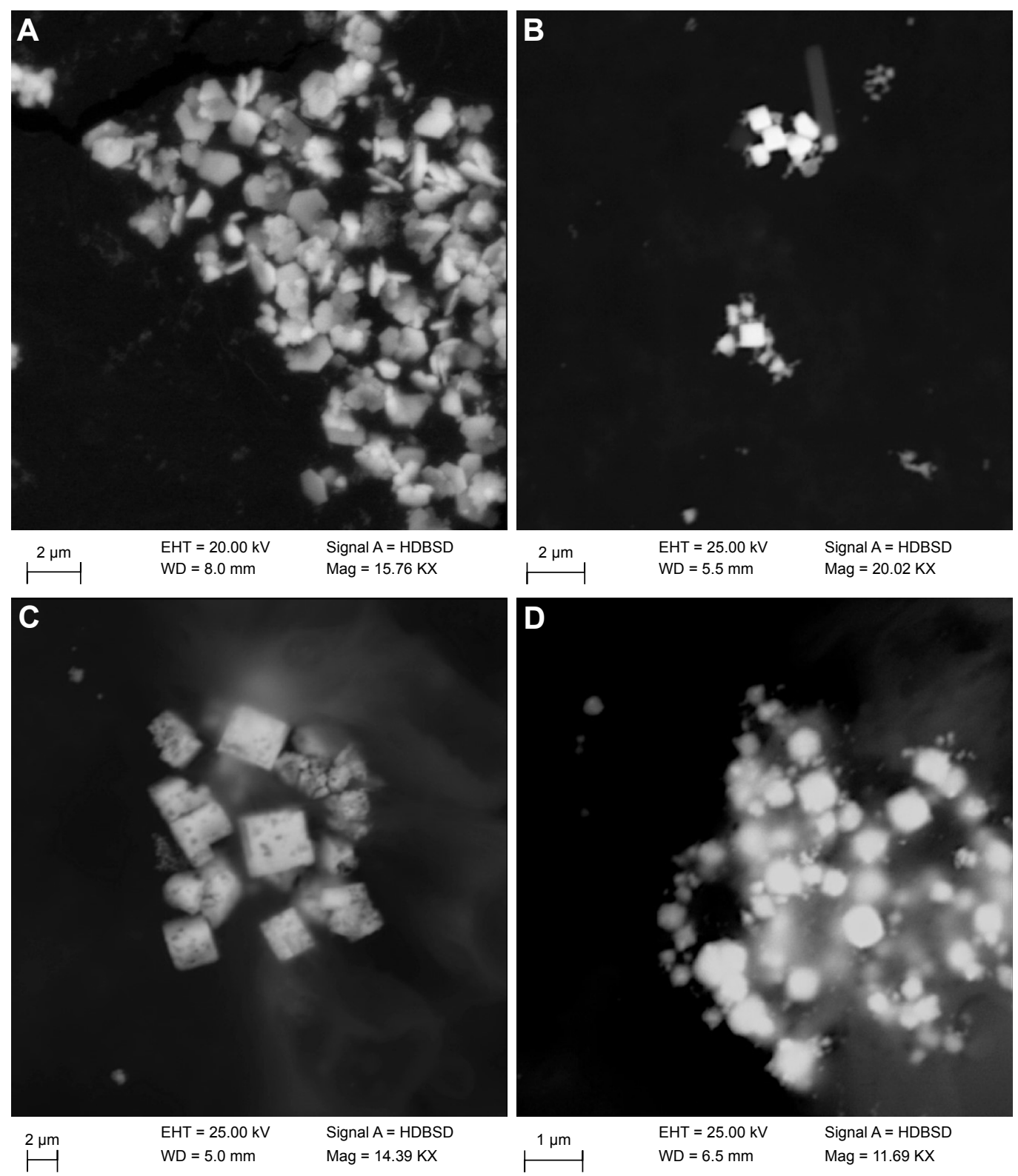

Figure 4 Scanning electron microscopy images of extracellularly biosynthesized silver nanoparticles: (A) run I ( $\mathrm{pH}^{2}, \mathrm{I} \mathrm{mM} \mathrm{AgNO}$ ), (B) run 3 ( $\mathrm{pH} 7,5 \mathrm{mM} \mathrm{AgNO}$ ), (C) run $2(\mathrm{pH} 9,1 \mathrm{mM} \mathrm{AgNO})_{3}$, and (D) run $5\left(\mathrm{pH} 8,3 \mathrm{mM} \mathrm{AgNO}_{3}\right)$. 
around $1,645 \mathrm{~cm}^{-1}$ a peak indicated the stretching vibration of the $[\mathrm{NH}] \mathrm{C}=\mathrm{O}$ group, characteristic of proteins, and $\mathrm{NH}$ stretch vibrations of amide II. ${ }^{45,46}$ The presence of carbohydrates was corroborated with the appearance of a small peak at $1,537 \mathrm{~cm}^{-1}$ (stretch of $\mathrm{C}=\mathrm{N}$ and $\mathrm{C}=\mathrm{C}$ in the benzene ring of aromatic compounds) and a peak at $1,051 \mathrm{~cm}^{-1}$ (stretching and bending of $\mathrm{C}-\mathrm{OH}$ or C-O groups) ${ }^{36}$ The FTIR spectra of the extracellularly biosynthesized AgNPs differed the most from the biomass spectra. The peak at $830 \mathrm{~cm}^{-1}$ could indicate the stretching of an alkene $\mathrm{C}-\mathrm{H}$ group, possibly belonging to the hydrocarbons $B$. braunii secretes into the culture medium. The peak at $1,051 \mathrm{~cm}^{-1}$ suffered a slight shift compared with the biomass spectra and could also be an indicator of the presence of the carbohydrates embedded in the ECM. ${ }^{20}$ The peak at $1,350 \mathrm{~cm}^{-1}$ became much more pronounced compared with the biomass spectra, while the

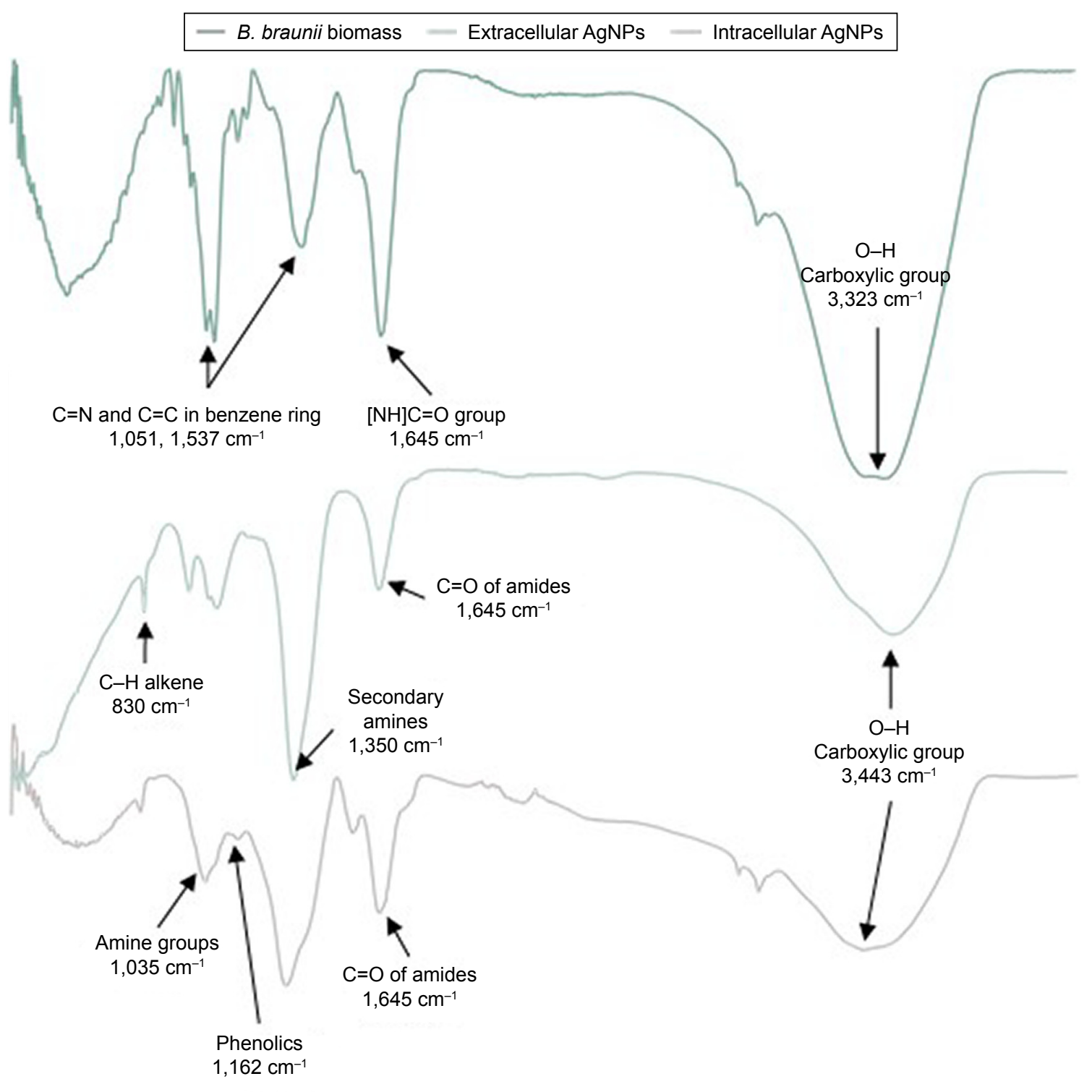

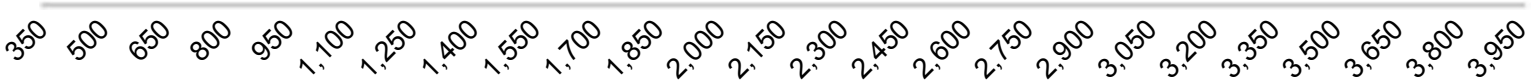

$$
\begin{aligned}
& \text { Wavenumber }\left(\mathrm{cm}^{-1}\right)
\end{aligned}
$$

Figure 5 FTIR spectrum of Botryococcus braunii biomass, extracellularly biosynthesized AgNPs (run I: $\mathrm{pH}$ 7, I mM AgNO ), and intracellularly biosynthesized AgNPs (run 7: pH 6, $3 \mathrm{mM} \mathrm{AgNO}{ }_{3}$ ).

Abbreviations: AgNPs, silver nanoparticles; FTIR, Fourier transform infrared. 
peak at $1,645 \mathrm{~cm}^{-1}$ remained practically identical, both indicators of the role that amide linkage and carbonyl and hydroxyl groups played in the biosynthesis of AgNPs.

The extracellular space $B$. braunii creates in the culture medium contains large amounts of hydrocarbons and polysaccharides, as confirmed by the FTIR spectra. Considering the fact that hydrocarbons are generally stable at different $\mathrm{pH}$ levels, we believe that other components released by the ECM are responsible for the synthesis of extracellular AgNPs. ${ }^{47}$ The spectra indicated the presence of amide, carbonyl, and hydroxyl groups in the sample, signaling polysaccharides, polyaldehydes, and proteins as the reducing, capping, and stabilizing agents. It is known that $B$. braunii is capable of producing and releasing high amounts of EPS into the culture medium as a protection and/or stress response measure. Studies showed that this microalga is capable of surviving extreme conditions, such as high temperatures, desiccation, and even ingestion by birds because of the EPS it releases. Therefore, by subjecting the algae to stress conditions, such as the presence of silver nitrate in the medium, the production of EPS would be increased, and the synthesis of AgNPs would take place. This same scenario was carried out with Calothrix pulvinata to produce AuNPs. ${ }^{45}$

In the intracellularly biosynthesized AgNPs, peaks at $\sim 1,035 \mathrm{~cm}^{-1}$ represented the vibrations of primary and secondary amines; ${ }^{30}$ the change in the peak at $1,162 \mathrm{~cm}^{-1}$ in relation to the biomass spectra may be taken as a sign of depletion of the phenolic residues. The peak at $1,035 \mathrm{~cm}^{-1}$ was also present, as was the peak at $1,645 \mathrm{~cm}^{-1}$, indicators of stretching vibrations of amine-related groups and $\mathrm{C}-\mathrm{O}$ or $\mathrm{C}-\mathrm{OH}$ groups, respectively. The peak at $1,537 \mathrm{~cm}^{-1}$ remained unchanged between the biomass spectra and the intracellularly synthesized AgNPs spectra, indicating that perhaps the molecules responsible for the reduction and stability of the biosynthesized AgNPs were proteins/peptides and carbohydrates. ${ }^{32}$

Due to the appearance of these stretching frequencies, it was concluded that carbohydrates and proteins were responsible for the synthesis, capping, and stabilization of AgNPs. Other studies have identified amino acids such as tryptophan, phenylalanine, and tyrosine as main reductive agents for Ag. However, B. braunii also contains a high amount of polyaldehydes in the ECM: This structure is formed of a polysaccharide layer embedded with algaenans as well as a backbone of long-chain polyaldehydes. ${ }^{20}$ Given the fact that the first interaction between Ag and the algal cell occurs at the cell wall, we believe that most of the AgNPs are synthesized in the ECM region due to the interaction between the silver nitrate and the components of the ECM and cell wall. Afterward, some of the Ag is diffused inside the cell and accumulates in the chloroplast, where the rest of the synthesis takes place due to the photosynthetic components of the organelle. ${ }^{48} \mathrm{~A}$ range of microalgae strains was reported to synthetize various NPs intracellularly or extracellularly, ${ }^{49}$ and our study shows that Botryococcus is capable of synthetizing NPs in both ways.

\section{Antimicrobial activity}

Due to the fact that most of the applications of AgNPs are based on their antimicrobial activity, it is important to test this property against known and varied pathogens. In this study, the antimicrobial activity of the biosynthesized AgNPs was tested against four microorganisms: two Gram-negative bacteria ( $E$. coli and P. aeruginosa), a Gram-positive bacteria (S. aureus), and the yeast C. albicans; in addition, a comparison with two controls was carried out: an ampicillin solution and a commercial AgNPs solution (Sigma-Aldrich) using the agar well diffusion method. Figure 6 shows the antimicrobial activity of the intracellularly synthesized AgNPs compared with the two controls. According to the analysis of variance, a significant effect of the synthesis method on the inhibition halo was found. All the intracellularly biosynthesized AgNPs displayed an antimicrobial activity against the bacteria, but not against the yeast, most likely due to the cell wall and the size of the particles. It has been stated that the smaller the NP, the more antimicrobial activity it has, due to the increased ability of the particle to cross the cellular membrane. The results of the antimicrobial tests support this statement, given that the intracellularly biosynthesized particles were smaller and also presented a higher antimicrobial activity compared with the extracellularly biosynthesized particles according to the statistical analysis. The spherical shape seemed to grant more antimicrobial activity against the pathogens, most likely due to the higher surface area. In our study, the more spherical-like particles such as the intracellular

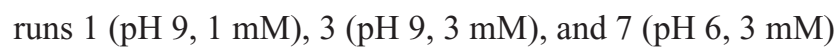
displayed a high antimicrobial effect, in accordance with several studies. ${ }^{50-52}$

While the size of the NP is one of the most influential aspects in terms of antimicrobial activity, it is not the only one: The amount of Ag that the NP contains can also influence the antimicrobial activity, as can the shape of the particle. Some studies have reported an increased antimicrobial activity in NPs with triangular shapes, due to the fact that the sharp corners of the NP can penetrate the cellular membrane more easily. ${ }^{53}$ This can explain why the biosyn- 


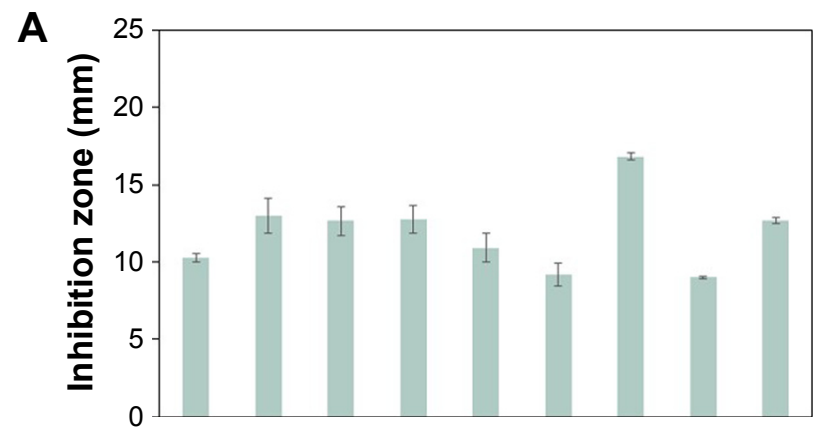

\section{C}

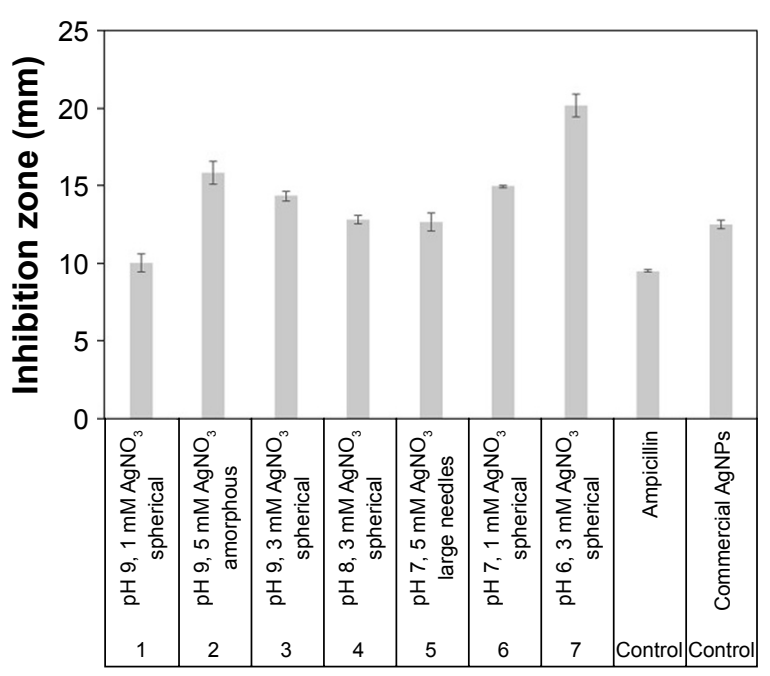

B

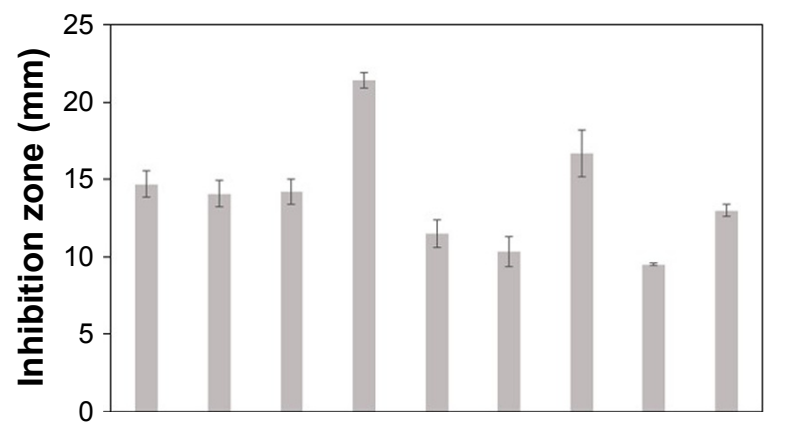

D

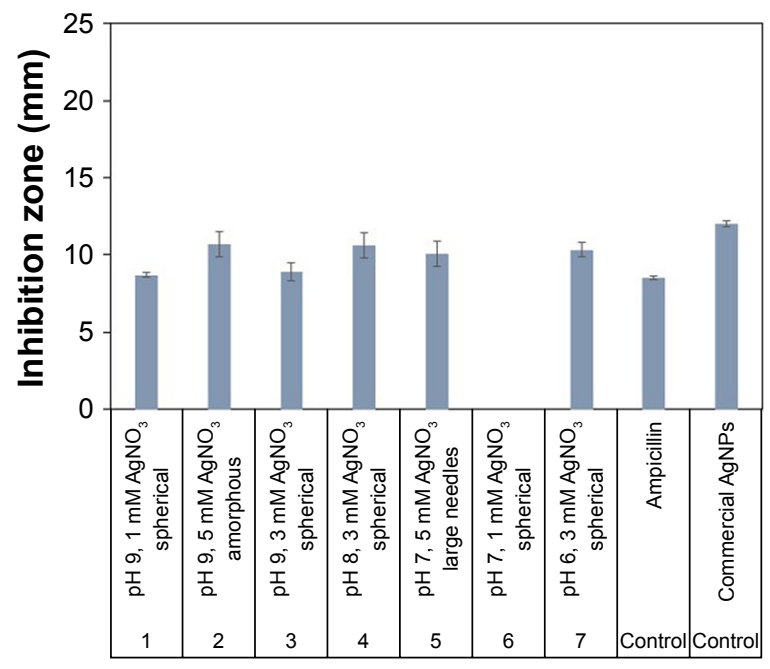

Figure 6 Antimicrobial activity and shape of the intracellularly biosynthesized AgNPs against selected pathogens: (A) Escherichia coli, (B) Pseudomonas aeruginosa, (C) Staphylococcus aureus, and (D) Candida albicans compared with ampicillin and a commercial AgNPs solution.

Abbreviation: AgNPs, silver nanoparticles.

thesized NPs displayed a higher antimicrobial effect when compared to the 20 -nm commercial AgNPs despite having a bigger size.

Post hoc test indicated that the highest inhibition effect was observed in $P$. aeruginosa and $S$. aureus. Regarding the effect of the different $\mathrm{pH}$ levels, statistically, the highest inhibition effect was observed at a $\mathrm{pH}$ of 6 and 8; the lowest inhibition was displayed at a $\mathrm{pH}$ level of 7 . The highest inhibition effect was reached with a silver nitrate concentration of $3 \mathrm{mM}$. The study previously mentioned regarding the biosynthesis of AgNPs with B. braunii also tested the antimicrobial activity against three of the four pathogens analyzed in this study: E. coli, P. aeruginosa, and $S$. aureus. ${ }^{17}$ Even though there is no mention of the concentration of NPs used in their antimicrobial assay, it is worthy to compare the results of both studies: in the case of $E$. coli and $P$. aeruginosa, the values obtained were similar to the study at hand; however, the NPs obtained at $\mathrm{pH}$ values of 6 and 8 yielded more antimicrobial effect against these two pathogens. In the case of S. aureus, most of the intracellularly biosynthesized particles obtained in this study yielded more antimicrobial activity.
Figure 7 represents the antimicrobial activity of the extracellularly biosynthesized AgNPs. All of the samples presented an antimicrobial effect against $E$. coli, but not all of them were effective against the rest of the pathogens. This is most likely due to the size and shape of the particles: Smaller cube particles such as those produced by run $3 \mathrm{pH} 7$, $5 \mathrm{mM}$ ) were effective against all the pathogens, while bigger particles such as those from run $2(\mathrm{pH} \mathrm{9,1} \mathrm{mM)} \mathrm{were} \mathrm{not.}$ Particles from runs $1(\mathrm{pH} \mathrm{7,1} \mathrm{mM)} \mathrm{and} 5(\mathrm{pH} \mathrm{8,3} \mathrm{mM)} \mathrm{were}$ effective against the Gram-negative bacteria, but did not have a significant effect against the Gram-positive bacteria and the yeast, most likely due to the composition of the cell wall of $S$. aureus and C. albicans. Runs $3(\mathrm{pH} 7,5 \mathrm{mM}), 4$ (pH 6, $3 \mathrm{mM})$, and $6(\mathrm{pH} 8,5 \mathrm{mM})$ presented an antimicrobial activity against all pathogens. The antimicrobial activity of AgNPs has been proven to be concentration-dependent. ${ }^{31}$ In this study, a $1 \mu \mathrm{g} / \mathrm{mL}$ concentration of AgNPs was used; our results showed that even at such a low concentration, the AgNPs displayed a higher antimicrobial effect than the controls, which were at higher concentrations (ampicillin was used at $2 \mu \mathrm{g} / \mathrm{mL}$ ), and the commercial AgNPs solution 

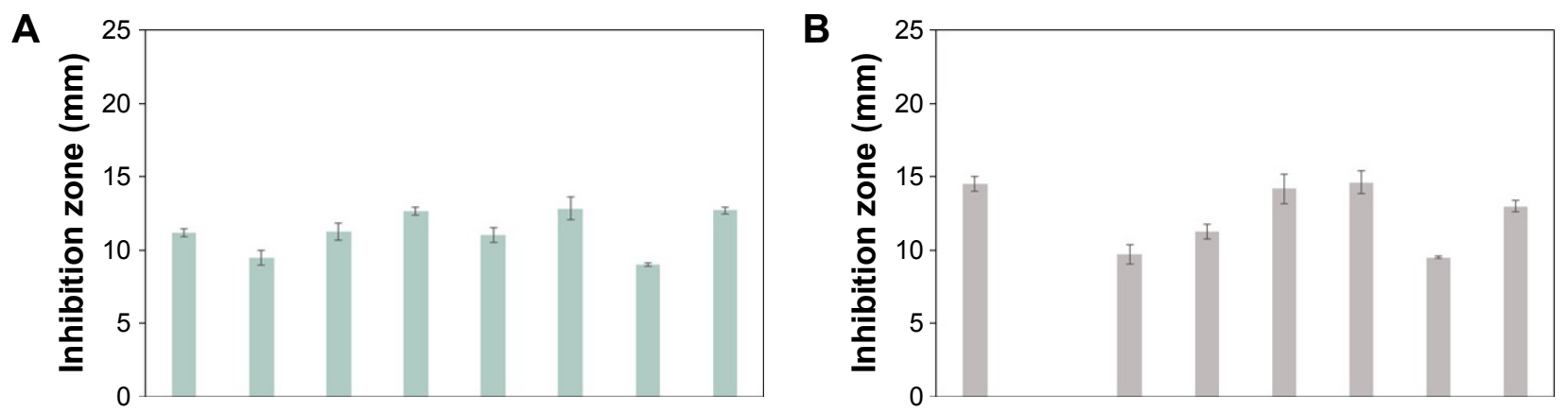

C

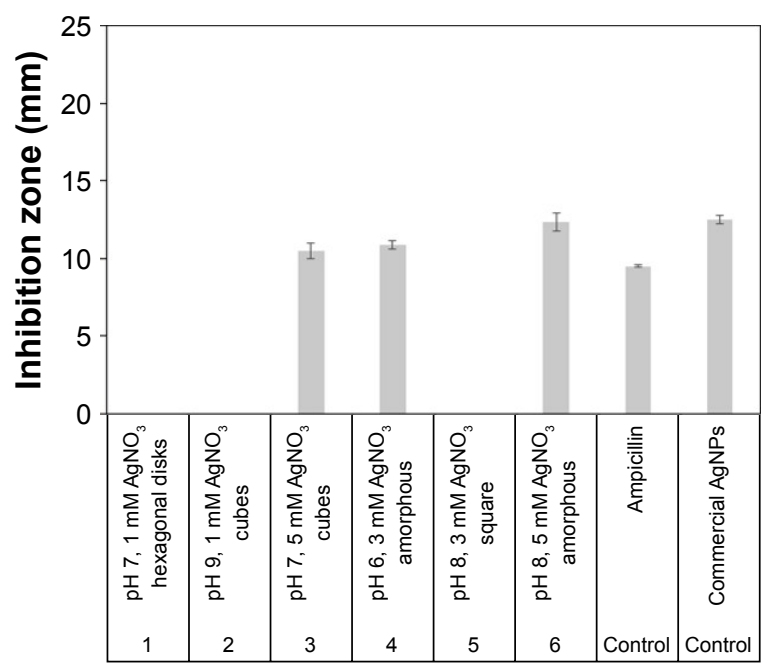

D

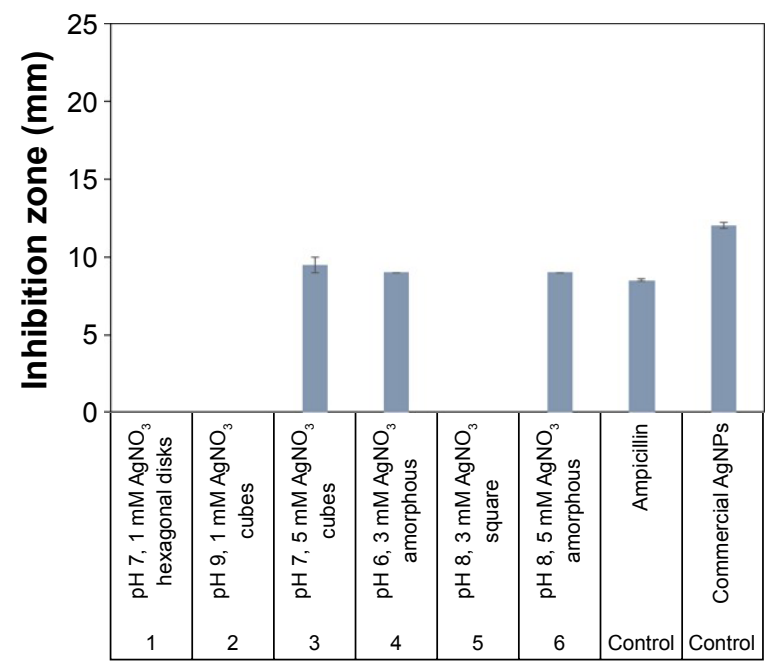

Figure 7 Antimicrobial activity and shape of the extracellularly biosynthesized AgNPs (A) Escherichia coli, (B) Pseudomonas aeruginosa, (C) Staphylococcus aureus, and (D) Candida albicans compared with an antibiotic solution and a commercial nanoparticle solution.

Abbreviation: AgNPs, silver nanoparticles.

was used at its default concentration of $0.02 \mathrm{mg} / \mathrm{mL}$. Besides antimicrobial activities, AgNPs synthetized by microalgae were also reported to possess anticancer activity ${ }^{54}$ Hence, it remains to be further explored whether our biogenic AgNPs possess anticancer and/or antioxidant effect.

Given the fact that overall the intracellularly synthesized AgNPs displayed more antimicrobial effect compared with the extracellularly synthesized AgNPs, it can be concluded that intracellular synthesis is a more effective method, perhaps due to the number of compounds responsible for the synthesis, if the intention is to apply these biogenic AgNPs for antimicrobial purposes. There are other areas of use for AgNPs that might not require the smallest size possible, such as textile functionalization, paint additives, and orthodontic implants. ${ }^{3,5,56}$ It is worth mentioning that biosynthesized AgNPs have been used as paint additives with promising results, ${ }^{57}$ in addition, wound healing tests using biosynthesized AgNPs have been carried out with positive results. ${ }^{58}$ A statistical comparison between the two methods of biosynthesis was performed by a comparison of means. Results indicated that the intracellularly biosynthesized AgNPs yielded a significantly more inhibiting effect compared with the extracellularly biosynthesized AgNPs. Afterward, an extra comparison was made between the intracellularly biosynthesized AgNPs and the controls. The results showed that the antibiotic produced a lower inhibition compared with the NPs; however, there was not a significant difference between the inhibiting effect of the NPs compared with the commercial AgNP solution.

\section{Conclusion}

The shape and size of AgNPs controlled by Ag concentration and $\mathrm{pH}$ under the intracellular and extracellular biosynthesis by $B$. braunii cultures were described. The intracellularly biosynthesized AgNPs had a predominant spherical shape, while those extracellularly biosynthesized presented more variety. The FTIR analysis confirmed the role of the components of the ECM in the synthesis of AgNPs. Antimicrobial assays revealed an activity against all pathogens tested, with the intracellularly biosynthesized AgNPs displaying an overall higher activity compared with the extracellularly biosynthesized AgNPs. Biosynthesis through B. braunii 
may be a valuable, greener, and cost-effective method for the generation of AgNPs with antimicrobial activity.

\section{Acknowledgments}

We are thankful for the financial support provided by Consejo Nacional de Ciencia y Tecnología de México (CONACyT Scholarship program, number 446308) as well as Tecnologico de Monterrey, School of Engineering and Science. This research has been partially funded by the Tec de Monterrey and MIT Nanotechnology Program. The support and assistance of LCQ Regina Vargas, MC Luz Elena Gómez del Campo Herrán, Dr Carmen Salinas, and Dr Elda Gómez are gratefully acknowledged.

\section{Disclosure}

The authors report no conflicts of interest in this work.

\section{References}

1. Gajbhiye S, Sakharwade S. Silver nanoparticles in cosmetics. JCDSA. 2016;06(01):48-53.

2. Arfat YA, Ahmed J, Hiremath N, Auras R, Joseph A. Thermomechanical, rheological, structural and antimicrobial properties of bionanocomposite films based on fish skin gelatin and silver-copper nanoparticles. Food Hydrocoll. 2017;62(Suppl C):191-202.

3. Pulit-Prociak J, Chwastowski J, Kucharski A, Banach M. Functionalization of textiles with silver and zinc oxide nanoparticles. Appl Surf Sci. 2016;385:543-553.

4. Mahdieh M,Zolanvari A, Azimee AS, Mahdieh M. Green biosynthesis of silver nanoparticles by Spirulina platensis. Sci Iran. 2012;19(3):926-929.

5. Shakibaie M, Forootanfar H, Golkari Y, Mohammadi-Khorsand T, Shakibaie MR. Anti-biofilm activity of biogenic selenium nanoparticles and selenium dioxide against clinical isolates of Staphylococcus aureus, Pseudomonas aeruginosa, and Proteus mirabilis. J Trace Elem Med Biol. 2015;29:235-241.

6. Rosa RM, Silva JC, Sanches IS, Henriques C. Simultaneous photoinduced cross-linking and silver nanoparticle formation in a PVP electrospun wound dressing. Mater Lett. 2017;207(Suppl C):145-148.

7. Fauss E. The Silver Nanotechnology Commercial Inventory. University of Virginia; 2008. Available from: http://www.nanotechproject.org/ process/assets/files/6718/fauss_final.pdf. Accesed June 20, 2018.

8. Kumar S, Bhattacharya W, Singh M, Halder D, Mitra A. Plant latex capped colloidal silver nanoparticles: a potent anti-biofilm and fungicidal formulation. J Mol Liq. 2017;230(Suppl C):705-713.

9. Lee W, Kim KJ, Lee DG. A novel mechanism for the antibacterial effect of silver nanoparticles on Escherichia coli. Biometals. 2014; 27(6):1191-1201.

10. SCENIHR (Scientific Committee on Emerging and Newly Identified Health Risks). Nanosilver: safety, health and environmental effects and role in antimicrobial resistance. Available from http://ec.europa.eu/ health/scientific_committees/emerging/docs/scenihr_o_039.pdf. Accessed June 20, 2018.

11. Berthet M, Gauthier Y, Lacroix C, Verrier B, Monge C. Nanoparticlebased dressing: the future of wound treatment? Trends Biotechnol. 2017; 35(8):770-784.

12. Graves JL, Tajkarimi M, Cunningham Q, et al. Rapid evolution of silver nanoparticle resistance in Escherichia coli. Front Genet. 2015;6:42.

13. Iravani S, Korbekandi H, Mirmohammadi SV, Zolfaghari B. Synthesis of silver nanoparticles: chemical, physical and biological methods. Res Pharm Sci. 2014;9(6):385-406.

14. Narayanan KB, Sakthivel N. Biological synthesis of metal nanoparticles by microbes. Adv Colloid Interface Sci. 2010;156(1-2):1-13.
15. Sharma D, Kanchi S, Bisetty K. Biogenic synthesis of nanoparticles: a review. Arab J Chem. Epub November 25, 2015. In press.

16. Singh R, Shedbalkar UU, Wadhwani SA, Chopade BA. Bacteriagenic silver nanoparticles: synthesis, mechanism, and applications. Appl Microbiol Biotechnol. 2015;99(11):4579-4593.

17. Patel V, Berthold D, Puranik P, Gantar M. Screening of cyanobacteria and microalgae for their ability to synthesize silver nanoparticles with antibacterial activity. Biotechnol Rep. 2015;5(1):112-119.

18. Zeraatkar AK, Ahmadzadeh H, Talebi AF, Moheimani NR, Mchenry MP. Potential use of algae for heavy metal bioremediation, a critical review. J Environ Manage. 2016;181:817-831.

19. Cheng P, Ji B, Gao L, Zhang W, Wang J, Liu T. The growth, lipid and hydrocarbon production of Botryococcus braunii with attached cultivation. Bioresour Technol. 2013;138:95-100.

20. Gouveia JD, Ruiz J, van den Broek LAM, et al. Botryococcus braunii strains compared for biomass productivity, hydrocarbon and carbohydrate content. J Biotechnol. 2017;248:77-86.

21. Dayananda C, Sarada R, Usharani M, Shamala T, Ravishankar G. Autotrophic cultivation of Botryococcus braunii for the production of hydrocarbons and exopolysaccharides in various media. Biomass Bioenergy. 2007;31(1):87-93.

22. Dubois M, Gilles KA, Hamilton JK, Rebers PA, Smith F. Colorimetric method for determination of sugars and related substances. Anal Chem. 1956;28(3):350-356.

23. Lowry OH, Rosebrough NJ, Farr AL, Randall RJ. Protein measurement with the Folin phenol reagent. J Biol Chem. 1951;193(1):265-275.

24. Barwal I, Ranjan P, Kateriya S, Yadav S. Cellular oxido-reductive proteins of Chlamydomonas reinhardtii control the biosynthesis of silver nanoparticles. J Nanobiotechnology. 2011;9(1):56.

25. Howe RA, Andrews JM. BSAC standardized disc susceptibility testing method (version 11). J Antimicrob Chemother. 2012;67(12): 2783-2784.

26. Díaz Bayona KC, Garcés LA. Effect of different media on exopolysaccharide and biomass production by the green microalga Botryococcus braunii. J Appl Phycol. 2014;26(5):2087-2095.

27. Rao AR, Dayananda C, Sarada R, Shamala TR, Ravishankar GA. Effect of salinity on growth of green alga Botryococcus braunii and its constituents. Bioresour Technol. 2007;98(3):560-564.

28. Lupi FM, Fernandes HML, Tomé MM, Sá-Correia I, Novais JM. Influence of nitrogen source and photoperiod on exopolysaccharide synthesis by the microalga Botryococcus braunii UC 58. Enzyme Microb Technol. 1994;16(7):546-550.

29. Allard B, Casadevall E. Carbohydrate composition and characterization of sugars from the green microalga Botryococcus Braunii. Phytochemistry. 1990;29(6):1875-1878.

30. Kumar SV, Rajeshkumar S. Optimized production of silver nanoparticles using marine macroalgae Sargassum myriocystum for its antibacterial activity. J Bionanosci. 2017;11(5):323-329.

31. Venkatesan J, Kim SK, Shim M. Antimicrobial, antioxidant, and anticancer activities of biosynthesized silver nanoparticles using marine algae Ecklonia cava. Nanomaterials. 2016;6(12):235

32. Chokshi K, Pancha I, Ghosh T, et al. Green synthesis, characterization and antioxidant potential of silver nanoparticles biosynthesized from de-oiled biomass of thermotolerant oleaginous microalgae Acutodesmus dimorphus. RSC Adv. 2016;6(76):72269-72274.

33. Salari Z, Danafar F, Dabaghi S, Ataei SA. Sustainable synthesis of silver nanoparticles using macroalgae Spirogyra varians and analysis of their antibacterial activity. J Saudi Chem Soc. 2016;20(4):459-464.

34. Kaliamurthi S, Selvaraj G, Çakmak ZE, Çakmak T. Production and characterization of spherical thermostable silver nanoparticles from Spirulina platensis (Cyanophyceae). Phycologia. 2016;55(5): $568-576$.

35. Jena J, Pradhan N, Nayak RR, et al. Microalga Scenedesmus sp.: a potential low-cost green machine for silver nanoparticle synthesis. J Microbiol Biotechnol. 2014;24(4):522-533.

36. Moreno-Garrido I, Pérez S, Blasco J. Toxicity of silver and gold nanoparticles on marine microalgae. Mar Environ Res. 2015;111:60-73. 
37. Suresh Kumar K, Dahms HU, Won EJ, Lee JS, Shin KH. Microalgaea promising tool for heavy metal remediation. Ecotoxicol Environ Saf. 2015;113:329-352.

38. Sintubin L, de Windt W, Dick J, et al. Lactic acid bacteria as reducing and capping agent for the fast and efficient production of silver nanoparticles. Appl Microbiol Biotechnol. 2009;84(4):741-749.

39. Mohandes F, Salavati-Niasari M. Sonochemical synthesis of silver vanadium oxide micro/nanorods: solvent and surfactant effects. Ultrason Sonochem. 2013;20(1):354-365.

40. Liguo Y, Yanhua Z. Preparation of nano-silver flake by chemical reduction method. Rare Metal Mat Eng. 2010;39(3):401-404.

41. Porrelli D, Travan A, Turco G, et al. Antibacterial-nanocomposite bone filler based on silver nanoparticles and polysaccharides. J Tissue Eng Regen Med. 2018;12(2):e747-e759.

42. Razack SA, Duraiarasan S. Nanosilver fabrication mediated by exopolysaccharides from Pseudomonas fluorescens and its biological activities. Am J Pharmtech Res. 2014;4(1):728-742.

43. Kanmani P, Lim ST. Synthesis and structural characterization of silver nanoparticles using bacterial exopolysaccharide and its antimicrobial activity against food and multidrug resistant pathogens. Process Biochem. 2013;48(7):1099-1106.

44. Selvakumar R, Aravindh S, Ashok AM, Balachandran YL. A facile synthesis of silver nanoparticle with SERS and antimicrobial activity using Bacillus subtilis exopolysaccharides. J Exp Nanosci. 2014;9(10): 1075-1087.

45. Brayner R, Barberousse H, Hemadi M, et al. Cyanobacteria as bioreactors for the synthesis of $\mathrm{Au}, \mathrm{Ag}, \mathrm{Pd}$, and Pt nanoparticles via an enzymemediated route. J Nanosci Nanotechnol. 2007;7(8):2696-2708.

46. Xia Q, Ma Y, Wang J. Biosynthesis of silver nanoparticles using Taxus yunnanensis Callus and their antibacterial activity and cytotoxicity in human cancer cells. Nanomaterials. 2016;6(9):160.

47. Wang M, Cui S, Yang X, Bi W. Synthesis of g-C3N4/Fe3O4 nanocomposites and application as a new sorbent for solid phase extraction of polycyclic aromatic hydrocarbons in water samples. Talanta. 2015; 132:922-928

48. Jeffryes C, Agathos SN, Rorrer G. Biogenic nanomaterials from photosynthetic microorganisms. Curr Opin Biotechnol. 2015;33:23-31.
49. Miazek K, Iwanek W, Remacle C, Richel A, Goffin D. Effect of metals, metalloids and metallic nanoparticles on microalgae growth and industrial product biosynthesis: a Review. Int J Mol Sci. 2015;16(10): 23929-23969.

50. Sonker AS, Pathak J, Kannaujiya VK, Sinha RP, Pathak J, Kannaujiya V. Characterization and in vitro antitumor, antibacterial and antifungal activities of green synthesized silver nanoparticles using cell extract of Nostoc sp. strain HKAR-2. Can J Biotech. 2017;1(1): 26-37.

51. Kumar M, Bansal K, Gondil VS, et al. Synthesis, characterization, mechanistic studies and antimicrobial efficacy of biomolecule capped and pH modulated silver nanoparticles. J Mol Liq. 2018;249:1145-1150.

52. Kumari M, Pandey S, Giri VP, et al. Tailoring shape and size of biogenic silver nanoparticles to enhance antimicrobial efficacy against MDR bacteria. Microb Pathog. 2017;105:346-355.

53. Pal S, Tak YK, Song JM. Does the antibacterial activity of silver nanoparticles depend on the shape of the nanoparticle? A study of the gram-negative bacterium Escherichia coli. J Biol Chem. 2015;290(42): 1712-1720.

54. Roychoudhury P, Gopal PK, Paul S, Pal R. Cyanobacteria assisted biosynthesis of silver nanoparticles - a potential antileukemic agent. J Appl Phycol. 2016;28(6):3387-3394.

55. Lin CC, Chen WY. Effect of paint composition, nano-metal types and substrate on the improvement of biological resistance on paint finished building material. Build Environ. 2017;117(Suppl C):49-59.

56. Venugopal A, Muthuchamy N, Tejani H, et al. Incorporation of silver nanoparticles on the surface of orthodontic microimplants to achieve antimicrobial properties. Korean J Orthod. 2017;47(1):3-10.

57. Lateef A, Azeez MA, Asafa TB, et al. Biogenic synthesis of silver nanoparticles using a pod extract of Cola nitida: antibacterial and antioxidant activities and application as a paint additive. JTUSCI. 2016;10(4): 551-562.

58. Chai SH, Wang Y, Qiao Y, et al. Bio fabrication of silver nanoparticles as an effective wound healing agent in the wound care after anorectal surgery. J Photochem Photobiol B. 2018;178:457-462.
International Journal of Nanomedicine

\section{Publish your work in this journal}

The International Journal of Nanomedicine is an international, peerreviewed journal focusing on the application of nanotechnology in diagnostics, therapeutics, and drug delivery systems throughout the biomedical field. This journal is indexed on PubMed Central, MedLine, CAS, SciSearch $®$, Current Contents ${ }^{\circledR} /$ Clinical Medicine,

\section{Dovepress}

Journal Citation Reports/Science Edition, EMBase, Scopus and the Elsevier Bibliographic databases. The manuscript management system is completely online and includes a very quick and fair peer-review system, which is all easy to use. Visit http://www.dovepress.com/ testimonials.php to read real quotes from published authors. 